\title{
Influence of Maturation Stages in Different Varieties of Wine Grapes (Vitis vinifera) on the Production of Ochratoxin A and Its Modified Forms by Aspergillus carbonarius and Aspergillus niger
}

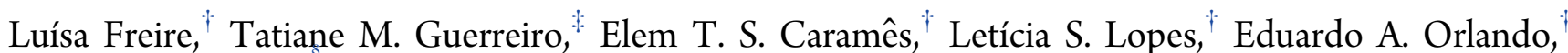
Giuliano E. Pereira, Juliana A. Lima Pallone, ${ }^{\dagger}$ Rodrigo R. Catharino, ${ }^{\ddagger}$ and Anderson S. Sant’Ana* ${ }^{* \dagger}$

${ }^{\dagger}$ Department of Food Science, Faculty of Food Engineering, University of Campinas, Campinas, SP, Brazil

${ }^{\ddagger}$ Innovare Biomarkers Laboratory, Faculty of Pharmaceutical Sciences, University of Campinas, Campinas, SP, Brazil

Brazilian Agricultural Research Corporation (Semiárido), Petrolina, PE, Brazil

Supporting Information

\begin{abstract}
Ochratoxin A is the main contaminant mycotoxin of grapes produced mainly by Aspergillus niger and Aspergillus carbonarius. Besides, it is possible that the formation of modified mycotoxin occurs through the plant defense mechanism or also by fungus actions itself. The objective of this study was to evaluate the influence of grape variety and maturation stage on the formation of OTA and modified mycotoxin. The determination of OTA was performed by high-performance liquid chromatography, and a high-resolution mass spectrometry was used for the detection of modified ochratoxin. A positive correlation was observed between the following grapes physicochemical parameters: $\mathrm{pH}$, total soluble solids, total glycosides in glucose, total anthocyanin, and OTA levels produced by A. niger and A. carbonarius. Therefore, the higher the concentrations of these parameters, the greater the production of mycotoxin in grapes. Among the elected targets, we identified the 14-decarboxyochratoxin A in Muscat Italia variety at veraison and 15 days after the beginning of veraison stages; and ethylamide-ochratoxin A as a biomarker in the Syrah variety at the ripeness stage.
\end{abstract}

KEYWORDS: conjugated mycotoxin, masked mycotoxin, mass spectrometry, modified mycotoxin, Vitis vinifera, food safety

\section{INTRODUCTION}

European Vitis vinifera grapes, which grow better in regions with a dry climate, high insolation, and low relative humidity, are the most used in wine production due to their specific organoleptic characteristics. ${ }^{1}$ However, there are many grape varieties and cultivars with distinct physicochemical and sensorial features in different producing regions. ${ }^{2}$ This variability, in addition to being responsible for the typicity of its derivatives, also influences the microbiological contamination of the grapes. ${ }^{3}$

The consumption of grapes and wines has been associated with beneficial health effects, due to the presence of phenolic compounds, which have antioxidant, anti-inflammatory, and bactericidal properties, and aid to prevent cardiovascular diseases. $^{4,5}$ However, microorganisms present in grapes, besides affecting grapevines health and being responsible for deterioration, may also produce toxic compounds to humans, such as mycotoxins.

Among mycotoxins, ochratoxin A (OTA) is the most commonly detected in grapes and their derivatives. OTA is produced mainly by Aspergillus niger and Aspergillus carbonarius. $^{3,6-8}$ Contamination of grapes by these species can occur since the beginning of maturation stage and becomes more prominent near harvest time, due to the increase of both relative humidity and temperature of the vineyard, besides changes in physicochemical characteristics: berry softening, sugars accumulation, and acidity reduction. ${ }^{9,10}$ However, it is possible that, besides grape deterioration and OTA production by these fungi, the production of modified mycotoxins still occurs in the vineyard.

The occurrence of mycotoxicoses that did not correlate with total levels of mycotoxin present in foods led to the emergence of the term masked mycotoxin, nowadays also called modified mycotoxin, characterized as conjugates formed from the defense metabolism in plants, which cannot be detected by traditional analytical methods. ${ }^{11}$

It is possible that these conjugates are formed at different stages of grape development. The formation of these conjugates is possible because plants have mechanisms that neutralize microbial toxins through detoxification by conjugation of endogenous metabolites. ${ }^{12}$ Such chemical modifications are obtained through hydrolysis, reduction, and oxidation reactions (Phase I metabolism) or by polar binding components (such as sugars) to the parent mycotoxin (Phase II metabolism). Such reactions facilitate sequestration of the compound formed in the vacuole or apoplast or its incorporation into cell wall components (Phase III metabolism), leading to a decrease in the toxicity of the metabolite formed. ${ }^{13-15}$ However, after ingestion of the conjugate, enzymes and components of human or animal microbiota may act on the modified mycotoxin, causing its hydrolysis, the

Received: April 28, 2018

Revised: July 1,2018

Accepted: July 26, 2018

Published: July 26, 2018 
release of the parent mycotoxin, and its absorption, increasing the individual's total exposure to the toxic compound. ${ }^{16}$

Several changes in physicochemical features of grapes occur throughout maturation. These reactions include the increase in berry size, color development, anthocyanins accumulation (in red grapes), berries softening due to the transformation of pectins, accumulation of sugars and reduction of organic acids, synthesis of volatile aromatic compounds, and reduction and polymerization of tannins. ${ }^{17}$ These changes have a direct influence on toxigenic fungi contamination. However, little is known about the effect of these parameters on OTA production by $A$. carbonarius and $A$. niger and the formation of modified mycotoxin. In this sense, this study aims to evaluate the influence of maturation stage and grape varieties on OTA production and modified mycotoxin formation.

\section{MATERIAL AND METHODS}

Safety Information. OTA is classified as a possible human carcinogen (group 2B). Therefore, it must be handled with care.

Wine Grapes. Different grape varieties (Syrah, Touriga Nacional, and Muscat Italia) were collected throughout maturation stage. The samples were collected at the beginning of the veraison (onset of maturation process); 15 days after the beginning of veraison; and ripeness (in which grapes reach optimum maturation point). Grapes were collected in a semiarid tropical region of Brazil located in the border between the states of Pernambuco and Bahia (Brazil) according to Freire et al. ${ }^{3}$

Physicochemical Characterization of Wine Grapes. For grape characterization, $15 \mathrm{~g}$ of each grape variety was weighed and mashed in a food processor (RI7761, Philips Walita, China) in triplicate for each analysis performed. Titratable acidity ( $\mathrm{g}$ of tartaric acid per $100 \mathrm{~g}$ of grape), total soluble solids (\% of soluble solids), and $\mathrm{pH}$ were determined according to AOAC. ${ }^{18}$ A digital refractometer was used to determine the total soluble solids (Pocket PAL-1, Atago, Ribeirão Preto, SP, Brazil). For $\mathrm{pH}$ determination, a digital potentiometer (K39-2014b, Kasvi, São José do Pinhais, SP, Brazil) was used. Sugars were determined according to a methodology previously described by Instituto Adolfo Lutz, ${ }^{19}$ and results were expressed as \% of total glycosides in glucose. Pectins were determined by gravimetry, and results were expressed as \% of pectic acid. ${ }^{19}$ Total monomeric anthocyanin levels were measured using the differential $\mathrm{pH}$ method ${ }^{20}$ and results expressed as mg equivalents of cyanidin-3-glycoside per $100 \mathrm{~g}$ of grape. Extraction used to determine phenolic compounds, and antioxidant activity was performed according to $\mathrm{Paz}$ et al. ${ }^{21}$ Determination of antioxidant activity was performed by $\mathrm{DPPH}^{22}$ and ORAC $^{23}$ methods, and results were expressed as DPPH value $(\mu \mathrm{Mol}$ Trolox equivalents per $100 \mathrm{~g}$ of grape) and ORAC value ( $\mu \mathrm{Mol}$ Trolox equivalents per $100 \mathrm{~g}$ of grape), respectively. Total phenolic compounds were obtained using the Folin-Ciocalteu reagent. ${ }^{24}$ Results were expressed as $\mathrm{mg}$ of gallic acid equivalents per $100 \mathrm{~g}$ of grape.

Inoculum Preparation. Strains of Aspergillus carbonarius (10614) and A. niger (10443), isolated from wine grapes and obtained from the Culture Collection of the Department of Food Science/CCDCAUFLA, were used in the experiments. These strains were previously selected in grape-based culture medium. ${ }^{25}$ Conidia suspensions of each species were prepared individually. ${ }^{26}$ Once suspensions were obtained, the final concentration of the inoculum was standardized at $10^{7}$ conidia $/ \mathrm{mL}$.

Grape Berry Inoculum. Twenty-five grams of grape berries from each sample were disinfected with $1 \%$ peracetic acid solution (Diversey, São Paulo, SP, Brazil) for 2 min and washed three times with sterile distilled water. After that, excessive water was withdrawn with the aid of a manual centrifuge. The inoculation was made by spraying (in laminar flow) $1.25 \mathrm{~mL}$ of each conidia suspension, individually, in triplicate. As a control, each grape variety at all maturation stage studied was inoculated with $1.25 \mathrm{~mL}$ of sterile distilled water without containing the conidial suspension. After inoculation, grapes were placed in plastic boxes previously disinfected with $1 \%$ peracetic acid solution for $30 \mathrm{~min}$. Then, the grapes were kept at $25^{\circ} \mathrm{C}$ for 7 days in the absence of light and under high relative humidity $(95 \pm 5 \%) \cdot{ }^{27}$ Relative humidity was controlled using a $\mathrm{K}_{2} \mathrm{SO}_{4}{ }^{28}$ saturated solution and measured throughout the incubation period with a hygrometer (LOG32TH, Incoterm, Porto Alegre, RS, Brazil). After the incubation period, samples were used for extraction.

Determination of OTA Concentration. Sample Preparation and Extraction. After grape homogenization with the aid of a pistil, 5 $\mathrm{g}$ of the sample were added to $25 \mathrm{~mL}$ of acetonitrile/water/formic acid (79:20.9:0.1, v/v/v) (JT Baker, Xalostoc, Mexico), vortexed, and extracted using a rotary shaker at $200 \mathrm{rpm}$ for $90 \mathrm{~min}$ at room temperature (Series 25 Shaker/Incubator, New Brunswick Scientific, Minnesota, USA). Following, the extracts were centrifuged at 10,000g for $10 \mathrm{~min}$ at $4{ }^{\circ} \mathrm{C}$ (Sorvall Legend Xtr, Thermo Scientific, Hampton, USA) according to Nathanail et al. with modifications. ${ }^{29}$ Supernatants obtained from the extraction procedure were filtered in polyvinylidene fluoride (PVDF, $0.22 \mu \mathrm{m}$ ) filter membranes units (Jet Biofil, Guangzhou, China) and used for quantification.

OTA Quantification by HPLC. For OTA quantification in grapes, an Agilent 1290 Infinity HPLC system (Agilent Technologies, Palo Alto, CA, USA) with a DAD detector set at a wavelength of $330 \mathrm{~nm}$ and an Agilent-Zorbax Eclipse XDB-C18 column $(4.6 \times 250 \mathrm{~mm}, 5$ $\mu \mathrm{m})$ were used. Flow and injection volume used were, respectively, $0.5 \mathrm{~mL} / \mathrm{min}$ and $20 \mu \mathrm{L}$. An isocratic system of acetonitrile/methanol/ aqueous acetic acid (35:35:29:1) (J.T Baker, Xalostoc, Mexico) was used for elution. A standard curve for OTA (Sigma-Aldrich, Darmstadt, Germany) was obtained using a stock solution previously prepared in methanol $(1 \mu \mathrm{g} / \mathrm{mL})$. Subsequently, standard solutions were prepared by serial dilutions, and their concentrations were of $0.00375,0.015,0.03,0.105$, and $0.135 \mu \mathrm{g} / \mathrm{mL}$. OTA quantification was performed after obtaining an analytical curve $[y=4987.8 x+$ 86.735; coefficient of determination $\left(R^{2}\right)=0.997$. Limits of detection (LD) and quantification (LQ) were 0.001 and $0.004 \mu \mathrm{g} /$ $\mathrm{g}$, respectively. Standard OTA solutions were injected in triplicate, and all samples were analyzed in duplicate.

For the recovery test, grape berries were fortified, in triplicate, at two levels $(1.0 \mu \mathrm{g} / \mathrm{g}$ and $3.0 \mu \mathrm{g} / \mathrm{g})$ and extracted as described above. Results of the recovery tests were $87.61 \%( \pm 5.38)$ and $112.64 \%$ $( \pm 6.06)$, respectively.

Identification of Modified Ochratoxin by HRMS. A mass spectrometer of the type ESI-LTQ-XL Orbitrap Discovery (Thermo Scientific, Bremen, Germany) with a nominal resolution of 30,000 (fwhm), a flow rate at $10 \mu \mathrm{L} / \mathrm{min}$, capillary temperature at $280{ }^{\circ} \mathrm{C}$, spray current set at $5 \mathrm{kV}$, and sheath gas at 5 arbitrary units was used for identification of the possible elected OTA derivatives (Table 1).

Table 1. Ochratoxin A and Its Derived Metabolites

\begin{tabular}{lll} 
& \multicolumn{1}{c}{ exact mass } & \\
\multicolumn{1}{c}{ metabolites } & $(\mathrm{g} / \mathrm{mol})$ & \multicolumn{1}{c}{ refs } \\
ochratoxin $\beta$ & 222.0528 & $52-54$ \\
$\alpha$-ochratoxin & 256.0139 & $52-55$ \\
$\alpha$-ochratoxin amide & 255.0298 & 47 \\
14-decarboxy-ochratoxin A & 359.0924 & $46-48,53$ \\
ochratoxin B & 369.1212 & $52-55$ \\
ochratoxin B methyl ester & 383.1369 & $52-54$ \\
ochratoxin B ethyl ester & 397.1525 & 52,54 \\
ochratoxin A & 403.0823 & $52-54$ \\
4-hydroxyochratoxin A & 419.0772 & $52-54$ \\
ethylamide ochratoxin A & 430.1296 & $54-56$ \\
ochratoxin A glucose ester & 565.1351 & 48,54 \\
(22 $\rightarrow$ 6') ochratoxin A-methyl- $\alpha$-D- & 579.1507 & 48 \\
$\quad$ glucopyranoside ester & & \\
ochratoxin A cellobiose ester & 727.1879 & 48 \\
ochratoxin A quinone & 383.1005 & 54,57 \\
ochratoxin A hydroquinone & 385.1162 & $53,54,57$ \\
ochratoxin C & 431.1136 & $52-55$
\end{tabular}


Table 2. Physicochemical Characterization of Grapes at Different Maturation Stages

\begin{tabular}{|c|c|c|c|c|}
\hline \multirow[b]{2}{*}{ physico-chemical characteristic } & \multirow[b]{2}{*}{ varieties } & \multicolumn{3}{|c|}{ maturation stages $^{a}$} \\
\hline & & veraison & 15 after veraison & ripeness \\
\hline \multirow[t]{3}{*}{$\mathrm{pH}$} & Syrah & $3.4^{\mathrm{Aa}} \pm 0.0$ & $3.9^{\mathrm{Ab}} \pm 0.0$ & $4.4^{\mathrm{Bc}} \pm 0.0$ \\
\hline & Touriga Nacional & $3.5^{\mathrm{Ba}} \pm 0.0$ & $3.9^{\mathrm{Ab}} \pm 0.1$ & $4.2^{\mathrm{Ac}} \pm 0.0$ \\
\hline & Muscat Italia & $4.1^{\mathrm{Ca}} \pm 0.0$ & $4.3^{\mathrm{Bb}} \pm 0.0$ & $4.3^{B c} \pm 0.0$ \\
\hline \multirow[t]{3}{*}{ titratable acidity ( $\mathrm{g}$ of tartaric acid/100 g) } & Syrah & $1.5^{\mathrm{Bc}} \pm 0.1$ & $0.6^{\mathrm{Bb}} \pm 0.0$ & $0.4^{\mathrm{Aa}} \pm 0.0$ \\
\hline & Touriga Nacional & $1.4^{\mathrm{Bc}} \pm 0.1$ & $0.8^{\mathrm{Cb}} \pm 0.0$ & $0.4^{\mathrm{Aa}} \pm 0.0$ \\
\hline & Muscat Italia & $0.5^{\mathrm{Ab}} \pm 0.0$ & $0.4^{\mathrm{Aa}} \pm 0.0$ & $0.5^{\mathrm{Aab}} \pm 0.0$ \\
\hline \multirow[t]{3}{*}{ total soluble solids (\%) } & Syrah & $12.5^{\mathrm{Ba}} \pm 0.0$ & $17.5^{\mathrm{Cb}} \pm 0.0$ & $22.5^{\mathrm{Cc}} \pm 0.0$ \\
\hline & Touriga Nacional & $7.5^{\mathrm{Aa}} \pm 0.0$ & $12.5^{\mathrm{Ab}} \pm 0.0$ & $17.5^{\mathrm{Ac}} \pm 0.0$ \\
\hline & Muscat Italia & $15.0^{\mathrm{Ca}} \pm 0.0$ & $15.0^{\mathrm{Ba}} \pm 0.0$ & $20.0^{\mathrm{Bb}} \pm 0.0$ \\
\hline \multirow[t]{3}{*}{ total soluble solids/titratable acidity } & Syrah & $8.3^{\mathrm{Aa}} \pm 0.3$ & $28.3^{\mathrm{Bb}} \pm 1.2$ & $57.2^{\mathrm{Bc}} \pm 3.8$ \\
\hline & Touriga Nacional & $6.3^{\mathrm{Aa}} \pm 1.6$ & $16.3^{\mathrm{Ab}} \pm 0.6$ & $44.5^{\mathrm{Ac}} \pm 3.0$ \\
\hline & Muscat Italia & $28.6^{\mathrm{Ba}} \pm 0.0$ & $41.2^{\mathrm{Cb}} \pm 1.7$ & $47.5^{\mathrm{Ab}} \pm 3.9$ \\
\hline \multirow[t]{3}{*}{$\%$ pectic acid } & Syrah & $0.5^{\mathrm{Aa}} \pm 0.1$ & $0.9^{\mathrm{ABb}} \pm 0.0$ & $0.9^{\mathrm{Ab}} \pm 0.0$ \\
\hline & Touriga Nacional & $1.2^{\mathrm{Cb}} \pm 0.0$ & $1.1^{\mathrm{Bb}} \pm 0.1$ & $0.9^{\mathrm{Aa}} \pm 0.1$ \\
\hline & Muscat Italia & $0.8^{\mathrm{Ba}} \pm 0.1$ & $0.8^{\mathrm{Aa}} \pm 0.1$ & $1.1^{\mathrm{Bb}} \pm 0.0$ \\
\hline \multirow[t]{3}{*}{$\%$ total glycosides in glucose } & Syrah & $9.4^{\mathrm{Ba}} \pm 0.1$ & $16.7^{\mathrm{Bb}} \pm 0.0$ & $21.0^{\mathrm{Bc}} \pm 0.2$ \\
\hline & Touriga Nacional & $6.6^{\mathrm{Aa}} \pm 0.0$ & $12.8^{\mathrm{Ab}} \pm 0.3$ & $17.9^{\mathrm{Ac}} \pm 0.4$ \\
\hline & Muscat Italia & $9.5^{\mathrm{Ba}} \pm 0.0$ & $13.2^{\mathrm{Ab}} \pm 0.0$ & $18.4^{\mathrm{Ac}} \pm 0.2$ \\
\hline \multirow[t]{3}{*}{ total anthocyanin (mg/100 g) } & Syrah & $26.7^{\mathrm{Aa}} \pm 2.3$ & $69.7^{\mathrm{Bb}} \pm 3.4$ & $106.2^{\mathrm{Bc}} \pm 5.4$ \\
\hline & Touriga Nacional & $19.3^{\mathrm{Aa}} \pm 5.4$ & $46.7^{\mathrm{Ab}} \pm 0.6$ & $82.2^{\mathrm{Ac}} \pm 4.5$ \\
\hline & Muscat Italia & $\mathrm{ND}^{b}$ & $\mathrm{ND}^{b}$ & $\mathrm{ND}^{b}$ \\
\hline \multirow[t]{3}{*}{ total phenolics (mg GAE/100 g) } & Syrah & $87.9^{\mathrm{Ba}} \pm 5.5$ & $144.9^{\mathrm{Bb}} \pm 14.8$ & $134.4^{\mathrm{Bb}} \pm 2.2$ \\
\hline & Touriga Nacional & $295.4^{\mathrm{Cc}} \pm 2.7$ & $145.7^{\mathrm{Ba}} \pm 8.2$ & $173.2^{\mathrm{Cb}} \pm 5.5$ \\
\hline & Muscat Italia & $39.2^{\mathrm{Aa}} \pm 1.8$ & $56.4^{\mathrm{Aa}} \pm 0.0$ & $39.6^{\mathrm{Aa}} \pm 2.0$ \\
\hline \multirow[t]{3}{*}{$\mathrm{DPPH}$ value $(\mu \mathrm{M} \mathrm{TE} / 100 \mathrm{~g})$} & Syrah & $49.1^{\mathrm{Ba}} \pm 6.2$ & $64.8^{\mathrm{Bb}} \pm 3.7$ & $50.0^{\mathrm{Ba}} \pm 4.9$ \\
\hline & Touriga Nacional & $157.1^{\mathrm{Cb}} \pm 11.1$ & $77.0^{\mathrm{Ba}} \pm 3.7$ & $86.6^{\mathrm{Ca}} \pm 2.5$ \\
\hline & Muscat Italia & $27.3^{\mathrm{Aa}} \pm 0.0$ & $38.6^{\mathrm{Aa}} \pm 1.2$ & $27.3^{\mathrm{Aa}} \pm 2.5$ \\
\hline \multirow[t]{3}{*}{ ORAC value $(\mu \mathrm{M}$ TE/100 g) } & Syrah & $5450.9^{\mathrm{Ba}} \pm 87.0$ & $9434.1^{B c} \pm 279.6$ & $7456.9^{\mathrm{Bb}} \pm 883.2$ \\
\hline & Touriga Nacional & $27845.2^{\mathrm{Cb}} \pm 672.8$ & $8502.2^{\mathrm{Ba}} \pm 116.0$ & $9593.3^{\mathrm{Ca}} \pm 27.0$ \\
\hline & Muscat Italia & $2468.6^{\mathrm{Aa}} \pm 123.6$ & $4014.0^{\mathrm{Ab}} \pm 27.4$ & $4889.6^{\mathrm{Ab}} \pm 166.3$ \\
\hline
\end{tabular}

${ }^{a}$ Average followed by lowercase letters compare the physicochemical characteristic in the line at maturation stages; and uppercase letters compare the physicochemical characteristic in the column at varieties. Different letters show a statistically significant difference at $p<0.05$. ${ }^{b} \mathrm{ND}:$ not detected.

An aliquot of $10 \mu \mathrm{L}$ of the obtained extract was diluted in $490 \mu \mathrm{L}$ of methanol and homogenized in a vortex for $30 \mathrm{~s}$. Then, a $1 \mu \mathrm{L}$ formic acid 100\% (Sigma-Aldrich, Darmstadt, Germany) was added, and direct injection of the extract was performed. Data were acquired in the survey scan mode and obtained in a positive mode in a mass range of $200-750 \mathrm{~m} / z$, in five replicates.

Statistical Analysis. The evaluation of the influence of grape varieties at different maturation stages on OTA production by $A$. carbonarius and $A$. niger was done through the analysis of variance with a posthoc Tukey test. Principal component analysis (PCA) was used to demonstrate the correlation between OTA production and physicochemical characteristics of grapes. Partial Least SquaresDiscriminant Analysis (PLS-DA), a multivariate regression method, was used as a tool to aid in the identification of modified mycotoxin. Online platform MetaboAnalyst 3.0, with the option Interquartile Range for data filtering and Normalization by a pooled sample from the group was used. ${ }^{30,31}$ Identification of the compounds was made through the comparison of their exact mass available in databases: METLIN (Scripps Center for Metabolomics, La Jolla, CA, USA) and literature references. These compounds were identified in order that a maximum error of $2 \mathrm{ppm}$ accuracy between the experimental and theoretical values was obtained.

\section{RESULTS AND DISCUSSION}

Physicochemical characteristics of the different grape varieties studied changed throughout maturation. An increase in $\mathrm{pH}$ (Syrah, 29.4\%; Touriga Nacional, 20\%; Muscat Italia, 4.9\%), total soluble solids (Syrah, 80\%; Touriga Nacional, 133.33\%; Muscat Italia, 33.33\%), and total glycosides in glucose (Syrah, 123.4\%; Touriga Nacional, 171.2\%; Muscat Italia, 93.7\%) was observed. Total anthocyanin levels also increased throughout maturation (Syrah, 297.8\%; Touriga Nacional, 325.9\%); however, this was not observed for the white variety (Muscat Italia) at all stages, as expected. Percentage of pectic acid also increased for all varieties (Syrah, 80\%; Muscat Italia, 37.5\%), except for Touriga Nacional, which exhibited the highest amounts of the compound at veraison stage, whereas a remarkable reduction was observed throughout maturation (25\%). Titratable acidity decreased for all varieties throughout maturation (Syrah, 73.3\%; Touriga Nacional, 71.4\%), except for Muscat Italia, which remains almost constant (Table 2).

Regarding the concentrations of total phenolic compounds and antioxidant activity (DPPH and ORAC), a different behavior was observed among varieties tested. In Syrah variety, an increase in the concentration of total phenolics compounds was found $(52.9 \%)$. In Touriga Nacional variety, a reduction (50.7\%) followed by an increase (18.9\%) was observed, and it remained constant in Muscat Italy variety. For antioxidant capacity (DPPH value), despite a similar behavior to the one observed for the concentrations of phenolics compounds, a higher concentration was observed at 15 days after the beginning of veraison stage for Syrah variety (64.8 uM TE/100 
Table 3. Production of Ochratoxin A $(\mu \mathrm{g} / \mathrm{g})$ by $A$. carbonarius and A. niger in Grapes during Maturation

\begin{tabular}{|c|c|c|c|c|}
\hline \multirow[b]{2}{*}{ species } & \multirow[b]{2}{*}{ varieties } & \multicolumn{3}{|c|}{ maturation stages $^{a}$} \\
\hline & & veraison & 15 after veraison & ripeness \\
\hline \multirow[t]{3}{*}{ A. niger } & Syrah & $81.05^{\mathrm{Aa}} \pm 0.82$ & $188.97^{\mathrm{Ac}} \pm 18.01$ & $148.04^{\mathrm{Ab}} \pm 18.26$ \\
\hline & Touriga Nacional & $73.44^{\mathrm{Aa}} \pm 1.68$ & $235.39^{\mathrm{Bb}} \pm 18.06$ & $235.52^{\mathrm{Bb}} \pm 14.84$ \\
\hline & Muscat Italia & $106.83^{\mathrm{Aa}} \pm 1.47$ & $168.10^{\mathrm{Ab}} \pm 2.53$ & $246.74^{B c} \pm 9.10$ \\
\hline \multirow[t]{3}{*}{ A. carbonarius } & Syrah & $96.87^{\mathrm{Ba}} \pm 0.16$ & $148.55^{\mathrm{Bb}} \pm 4.14$ & $93.93^{\mathrm{Aa}} \pm 2.27$ \\
\hline & Touriga Nacional & $73.35^{\mathrm{Aa}} \pm 4.53$ & $144.39^{\mathrm{Bb}} \pm 4.35$ & $159.99^{\mathrm{Bb}} \pm 3.78$ \\
\hline & Muscat Italia & $152.75^{\mathrm{Cb}} \pm 3.17$ & $105.36^{\mathrm{Aa}} \pm 17.52$ & $115.21^{\mathrm{Aa}} \pm 11.39$ \\
\hline
\end{tabular}

${ }^{a}$ Average followed by lowercase letters compare the OTA levels in the line at maturation stages; and uppercase letters compare the OTA levels in the column at varieties. Different letters show a statistically significant difference at $p<0.05$.
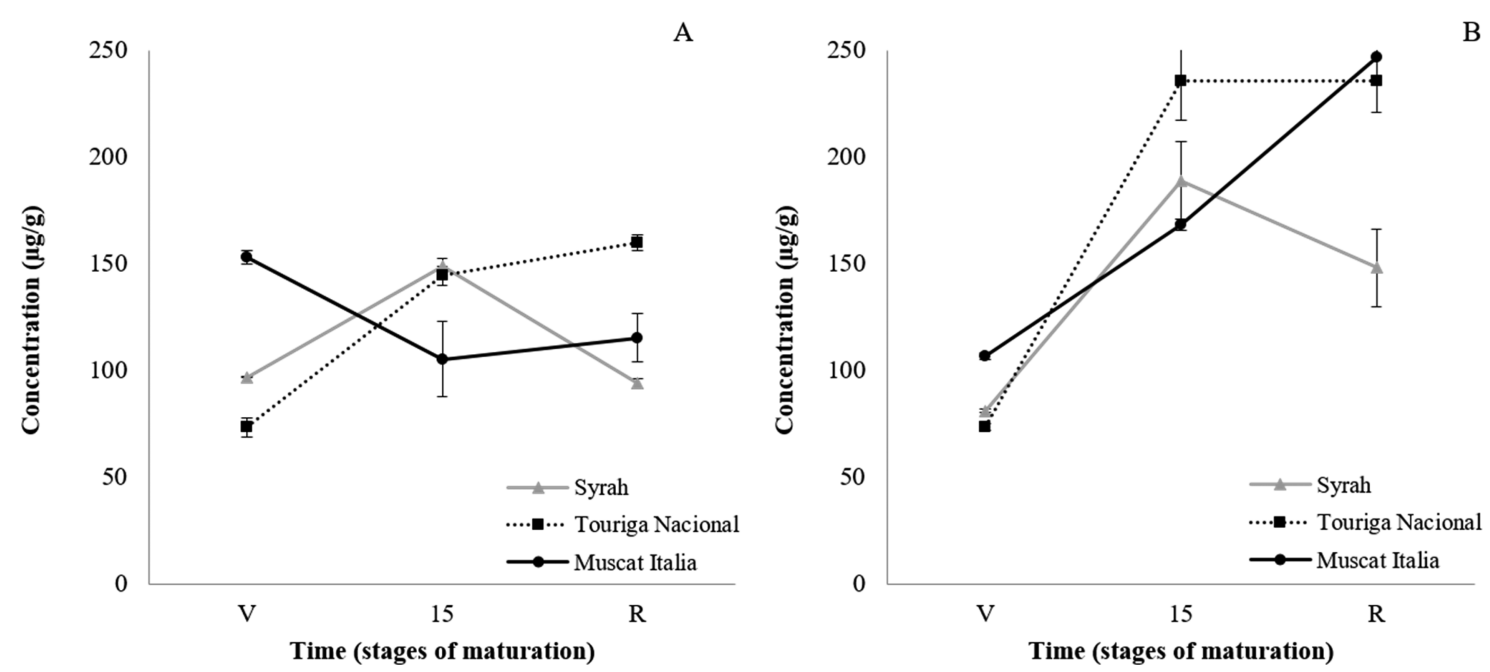

Figure 1. OTA production $(\mu \mathrm{g} / \mathrm{g})$ by $A$. carbonarius (A) and A. niger (B) strains in grapes over maturation.

g). A similar behavior between ORAC and DPPH was observed, except for Muscat Italy variety, which exhibited increased levels of ORAC over maturation (98.1\%).

Levels of the physicochemical parameters obtained were also different among varieties considering the same maturation stage. Muscat Italia variety presented higher $\mathrm{pH}$ values (4.1 to $4.3)$ and, therefore, a lower percentage of titratable acidity ( 0.4 to $0.5 \mathrm{~g}$ of tartaric acid/100 g) at all maturation stages studied. Syrah variety showed a higher percentage of total soluble solids (12.5\% to $22.5 \%)$ and total glycosides in glucose (9.4 to $21 \%$ ) in most of the stages evaluated. A higher concentration of total anthocyanin was also observed in this variety $(106.2 \mathrm{mg} / 100$ g). Touriga Nacional variety showed the highest percentage of pectic acid in most stages ( 1.2 to $0.9 \%$ ), except at ripeness stage, in which the highest percentage was observed for Muscat Italia (1.1\%). Higher concentrations of total phenolics compounds and antioxidant capacity (DPPH value and ORAC value) were also observed in Touriga Nacional variety in most maturation stages evaluated, 295.4 to $145.7 \mathrm{mg} \mathrm{GAE} /$ $100 \mathrm{~g} ; 157.1$ to $77.0 \mu \mathrm{M} \mathrm{TE} / 100 \mathrm{~g} ; 27,545.15$ to $8,502.24 \mu \mathrm{M}$ $\mathrm{TE} / 100 \mathrm{~g}$, respectively.

A higher OTA production by $A$. niger species was observed in all varieties and maturation stages, except in veraison stage, in which $A$. carbonarius produced higher levels of the mycotoxin (Table 3 ). Levels of OTA produced by $A$. niger ranged from $73.44 \mu \mathrm{g} / \mathrm{g}$ in Touriga Nacional variety at the veraison stage to $246.74 \mu \mathrm{g} / \mathrm{g}$ in Muscat Italia variety at ripeness stage. For A. carbonarius, the lowest OTA production was also observed at veraison stage for Touriga Nacional variety $(73.35 \mu \mathrm{g} / \mathrm{g})$; however, its highest production was detected in Touriga Nacional variety at ripeness stage (159.99 $\mu \mathrm{g} / \mathrm{g}$ ). Although most studies consider $A$. carbonarius the main OTA-producing species at higher levels, some strains of $A$. niger may be higher producers than $A$. cabonarius. ${ }^{32}$ In addition to $A$. niger being a good competitor, the microorganism adapts extremely well to the environment present in vineyards and grapes. ${ }^{33}$ Thus, the highest OTA production by this species in the grape varieties tested may be related to a better substrate adaptation. However, the best growth conditions are not always related to the higher production of secondary metabolites. These same isolates presented different behavior when evaluated in a grape-based culture medium in which $A$. niger produced lower amounts of OTA compared to $A$. carbonarius. ${ }^{25}$ These results demonstrate the importance of experiments performed directly in the food.

Both Aspergillus carbonarius and A. niger species were able to produce OTA at all stages of maturation, although OTA levels observed were different. An increase in mycotoxin levels produced by $A$. niger throughout maturation was detected for all varieties (Touriga Nacional, 220.70\%; Muscat Italia, $130.96 \%$ ), except for Syrah, which exhibited the highest levels of OTA at the 15 days after the beginning of veraison stage $(188.97 \mu \mathrm{g} / \mathrm{g})$, whereas reduced levels of the compound were observed at ripeness stage $(148.04 \mu \mathrm{g} / \mathrm{g})$. Similar behavior was observed for OTA production by $A$. carbonarius, except for Muscat Italia variety, in which the highest levels of the mycotoxin were obtained at veraison stage $(152.75 \mu \mathrm{g} / \mathrm{g})$ (Figure 1). 

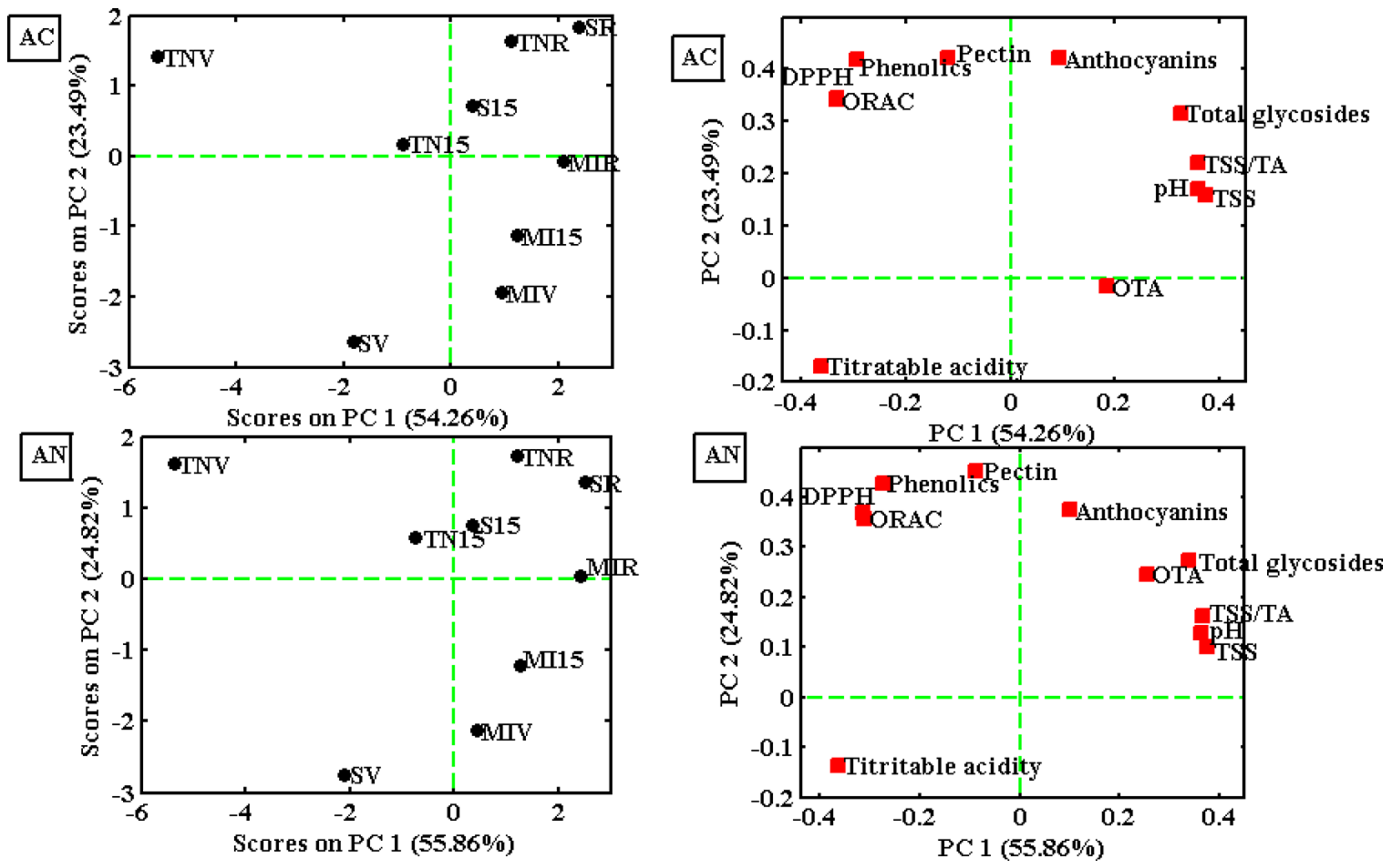

Figure 2. Principal components analysis for physicochemical characterization of grapes and OTA production by A. carbonarius (AC) and A. niger (AN), where TSS = total soluble solids; TSS-TA = total soluble solids/titratable acidity; $\mathrm{V}=$ veraison; $15=15$ days after the beginning of veraison; $\mathrm{R}=$ ripeness; $\mathrm{MI}=$ Muscat Italia; $\mathrm{S}=$ Syrah; $\mathrm{TN}=$ Touriga Nacional.

Expression of strain biosynthetic genes responsible for mycotoxins production may be related to the modification of nutritional factors of the plant by the pathogen itself or natural chemical components present in the plant. $^{34}$ Complex interactions between intrinsic and extrinsic factors (geographic location, cultivation and management practices, the microclimate of the region, microbial competition, grape variety, and maturation stage) will determine both the growth of toxigenic fungi and OTA production. ${ }^{35}$

Due to changes that occur during maturation, the period between early veraison and harvest is critical for the growth of ochratoxigenic fungi and consequently for OTA production. Grape variety also has influence in this contamination. ${ }^{36}$ Jiang et al. $^{37}$ detected different OTA levels in Thompson seedless (white, low seedless storability) (30.341 ng/mL), Kyoho (red, seeded, average storability) $(13.807 \mathrm{ng} / \mathrm{mL})$, and Red Earth (red, seeded, high storability) $(0.5 \mathrm{ng} / \mathrm{mL})$ grapes produced by A. carbonarius, artificially inoculated, and determined over 6 days at $25{ }^{\circ} \mathrm{C}$. Presence of the fungus also led to changes in physicochemical features of the grapes due to nutritional requirements and action of its enzymatic complex in the hydrolysis of some compounds.

Lasram et al. ${ }^{38}$ observed a higher OTA production by $A$. carbonarius in early veraison stage at Cabernet Sauvignon variety. At this stage, lower levels of sugar and higher levels of acidity were determined. Moreover, a reduction in mycotoxin levels throughout maturation was observed in which there was an increase in sugars and a reduction in acidity. However, an increase in OTA levels in the surmaturity stage was observed. In this stage, no significant change was observed for these physicochemical parameters, and therefore, the increase in mycotoxin levels may be related to facilitation of fungus penetration, probably due to the softening of the berries. Although we observed a similar result for Moscato Italia variety contaminated with $A$. carbonarius ( $24.58 \%$ reduction), an increase in OTA production was observed in the other varieties throughout maturation. This indicates an influence of grape variety on ochratoxin A production.

Even though higher levels of OTA have been detected in late maturation stages, this mycotoxin seems to be present since early stages. Therefore, although more advanced stages of maturation favor fungal growth, if the microorganism is present in early stages, the mycotoxin will most likely be produced. ${ }^{9,38}$

OTA levels were also different among grape varieties at the same maturation stage. Toxin levels produced by $A$. niger did not differ in veraison stage. After 15 days of the beginning of veraison stage, higher production of the mycotoxin was observed for Touriga Nacional variety $(255.39 \mu \mathrm{g} / \mathrm{g})$. At ripeness stage, the highest OTA levels were produced in Touriga Nacional $(235.52 \mu \mathrm{g} / \mathrm{g})$ and Muscat Italia (246.74 $\mu \mathrm{g} / \mathrm{g}$ ) varieties. For $A$. carbonarius, at veraison stage, the highest OTA production was observed in Muscat Italia variety $(152.75 \mu \mathrm{g} / \mathrm{g})$. After 15 days of the beginning of veraison stage, higher concentrations were observed for Syrah (148.55 $\mu \mathrm{g} / \mathrm{g})$ and Touriga Nacional $(144.39 \mu \mathrm{g} / \mathrm{g})$ varieties; and at ripeness stage for Touriga Nacional variety $(159.99 \mu \mathrm{g} / \mathrm{g})$.

The results indicate the influence of both variety and maturation stage of the grapes. Besides, fungal species also have a direct influence on the levels of mycotoxins produced. Therefore, principal component analysis (PCA) was performed to demonstrate a possible correlation between physicochemical parameters of the grapes and OTA production by A. niger and A. carbonarius (Figure 2). The data were autoscaled. The first four PC (principal components) explained $96.46 \%$ of the variability in data obtained for $A$. carbonarius, and the first two PC explained $80.68 \%$ of the variability in data obtained for $A$. niger. Through the principal component 1, a positive correlation was observed between the following physicochemical parameters: $\mathrm{pH}$, total soluble solids, total glycosides in glucose and total anthocyanin, and OTA levels. Therefore, the higher the concentrations of these parameters, the greater the production of mycotoxin by $A$. niger. In contrast, a negative 
correlation was observed between the following physicochemical parameters: titratable acidity, pectic acid, total phenolic compounds, and antioxidant activity (DPPH value and ORAC value). Thus, the higher the concentration of these parameters, the lower the OTA production. According to PC1 evaluation, similar correlations were observed for OTA production by $A$. carbonarius, although such correlation appears to be stronger for $A$. niger.

Growth and production of metabolites by filamentous fungi are closely linked to substrate composition. Different carbon sources and levels of sugars available are closely related to induction of the production of enzymes responsible for hydrolysis and nutrients utilization. ${ }^{39}$ OTA production by $A$. carbonarius was variable in the presence of different carbon sources. ${ }^{40}$ A positive correlation between total pectin content of the grapes and A. carbonarius presence was evidenced. ${ }^{3}$ In contrast, inhibition of pectinases production by Aspergillus japonicus was observed when glucose, sucrose, and pectin concentrations were excessive. ${ }^{39}$ As observed in the present study, an increase in OTA production by $A$. carbonarius was directly proportional to an increase in $\mathrm{pH}$ up to $4.0 .^{40}$ OTA production by this species was also affected by $\mathrm{pH}$ and chemical parameters of grape at the different maturation stages. ${ }^{38}$ Therefore, stimulation or inhibition of fungal growth and production of primary and secondary metabolites is directly related to the levels that these compounds are found in the substrate.

Some antioxidant compounds had a positive correlation with OTA production by several species belonging to the genus Aspergillus, whereas other species showed a negative correlation, suggesting the role of structure-dependent signals. ${ }^{41}$ The concentration of these compounds will also influence mycotoxin production. ${ }^{42}$

Although a positive correlation has been previously demonstrated between $A$. niger and phenolic compounds $[(-)$-epicatechin, procyanidin $\mathrm{A} 2$, procyanidin $\mathrm{B} 2$, rutin, isohamnetin-3-O-glycoside, and phenolic and gallic acids] and between $A$. carbonarius and (-)-gallate epicatechin present in grapes, ${ }^{3}$ in our work, a negative correlation between OTA production and phenolic compounds was observed, which indicates a possible antagonistic effect of the some grapes phenolic compounds against the production of fungal metabolites. Even though, mycotoxin production was not inhibited. However, the contamination of grapes by fungi of the genus Aspergillus is very common. This paradox indicates that the relationship between the physicochemical composition of the grapes and their contamination by toxigenic fungi seems to be a complex issue. ${ }^{41}$

In addition to OTA production, some toxigenic fungi are also able to produce modified mycotoxin through their enzymatic complex, which acts on the metabolism of the parent mycotoxin. ${ }^{25,43}$ Moreover, plants are also able to modify parent mycotoxins through their defense mechanisms (phase I and II metabolism). ${ }^{12}$ To search for these metabolites we used high-resolution mass spectrometry (HRMS) and PLS-DA.

The loadings plot of the statistical model formed by features selected by PLS-DA indicated the 65 main candidate biomarkers. From this list of ions, a search for modified mycotoxins was performed. Only two candidate OTA derivatives were identified among the elected targets (Table 1). Modified ochratoxins were identified only in the tests performed with $A$. niger. Candidate biomarkers identified were 14-decarboxy-ochratoxin $A\left([\mathrm{M}+\mathrm{Na}]^{+}: 382.0815\right)$ in Muscat
Italia variety at maturation stages: veraison and 15 days after the beginning of veraison and ethylamide-ochratoxin $\mathrm{A}([\mathrm{M}+$ $\left.\mathrm{K}]^{+}: 469.0939\right)$ in the Syrah variety at ripeness stage.

Candidate ethylamide-ochratoxin A was previously identified in the grape-based medium after $A$. niger inoculation throughout 21 days. It is possible that such a molecule may have been formed from the metabolism of the fungus itself. ${ }^{25}$ Fusarium spp. has already demonstrated the ability to form ZEN sulfates through the metabolism of parent mycotoxin $(\mathrm{ZEN})^{44}$

However, some metabolites can also be formed from the interaction between mycotoxigenic fungus and host, due to an effort of the plant for detoxification. ${ }^{13}$ Seven putative phase I and 18 putative phase II metabolites of ZEN were identified by Rolli et al. in durum wheat. ${ }^{45}$ The reductive and oxidative hydroxylation, followed by glycosylation and malonyl-conjugation, are major biotransformation pathways of $\mathrm{ZEN}$ as a response to wheat detoxification. ${ }^{45}$

Some molecules searched in this work were initially described as OTA derivatives formed from thermal processes: ochratoxin $\alpha$, ochratoxin $\alpha$-amide, 14-decarboxy-ochratoxin $\mathrm{A}$, and 14- $(R)$-ochratoxin $A{ }^{46,47}$ Moreover, it is possible that the OTA binds to food components. The conjugating compounds, ochratoxin A disaccharide esters and ochratoxin A monosaccharide esters, were identified during coffee roasting. ${ }^{48}$ Therefore, the formation of modified OTA can occur throughout the production chain: still in the field, by microorganisms or by processing. ${ }^{49}$ However, based on our findings, it is not possible to ensure that the metabolites identified (ethylamide-ochratoxin A and 14-decarboxy-ochratoxin A) have been produced by the fungus metabolism or as a plant defense mechanism.

OTA derivatives including ochratoxin $\alpha$, 4S-hydroxyochratoxin A, $4 R$-hydroxychratoxin A, hydroxychratoxin A- $\beta$-glucoside, ochratoxin A methyl ester, and other unidentified polar metabolites have been previously detected in plant-cell suspension cultures (carrots, tomatoes, cotton, soybeans, wheat, barley, and potatoes) contaminated with OTA. The metabolism of OTA occurred at different times in the cultures evaluated. Production of enzymes specifically capable of metabolizing the ochratoxin may be responsible for this difference. $^{50}$ Therefore, it is possible that the detoxification process of OTA in plants is related to the performance of enzymes in the conjugation or cleavage of the ochratoxin forming modified ochratoxin. ${ }^{25}$

Although the formation of these compounds, still in the plant, has the main purpose of detoxification, some of them, such as hydroxyochratoxin A- $\beta$-glucoside, can be cleaved by humans and animal metabolism or through food processing, releasing the parent mycotoxin and increasing the overall toxicity of food. ${ }^{50}$

It is interesting to highlight that 14-decarboxy-ochratoxin A, a degradation compound, appeared at the initial stages of maturation in which OTA levels were lower $(106.83 \mu \mathrm{g} / \mathrm{g}$ in veraison and $168.10 \mu \mathrm{g} / \mathrm{g}$ in 15 days after the begging of veraison) when compared to others. However, ethylamideochratoxin A, a conjugation compound, appeared in the late stage of maturation with an intermediate OTA level (148.04 $\mu \mathrm{g} / \mathrm{g}$ ). A correlation between OTA levels and the presence of modified ochratoxin cannot be made yet. However, some studies indicate that the correlation between parent mycotoxin and modified mycotoxin may exist up to a threshold concentration of parent mycotoxin, and above that, parent 
mycotoxin conversion might be reduced. Therefore, it is possible the there is a limitation in plant defense metabolism when it is highly contaminated by mycotoxin. ${ }^{51}$ It is possible that other physicochemical parameters not evaluated in this study may affect grapes contamination by toxigenic fungi and, consequently, OTA production. Moreover, the species also behave differently in the same substrate.

According to our findings, the production of OTA can occur from the initial stages of maturation, which indicates the importance of adoption of good agricultural and production practices throughout all stages of production and not only near the harvest, as occurs in some vineyards. In addition, it is of fundamental importance that predictive analyzes and risk assessments cover a higher number of species and different grape varieties to assist in a better understanding of the ecosystem related to the growth and production of secondary metabolites by fungi in the wine environment, thus ensuring safety and quality of grapes and their derivatives.

\section{ASSOCIATED CONTENT}

\section{S Supporting Information}

The Supporting Information is available free of charge on the ACS Publications website at DOI: 10.1021/acs.jafc.8b02251.

Spectra containing the precursor ion and their respective products ions (PDF)

\section{AUTHOR INFORMATION}

\section{Corresponding Author}

*E-mail: and@unicamp.br.

\section{ORCID}

Anderson S. Sant'Ana: 0000-0001-5052-2315

\section{Notes}

The authors declare no competing financial interest.

\section{ACKNOWLEDGMENTS}

L.F. acknowledges the financial support of São Paulo Research Foundation (Grant \#2016/21041-5), São Paulo Research Foundation (FAPESP), and the donation of fungi strains by the Culture Collection of the Department of Food Science/ CCDCA-UFLA. A.S.S.A. acknowledges the support of Conselho Nacional de Desenvolvimento Cientifico e Tecnológico (CNPq) (Grants \#302763/2014-7, \#305804/2017-0) and Coordenação de Aperfeiçoamento de Pessoal de Nível Superior (CAPES) (Grant \#33003017027P1).

\section{REFERENCES}

(1) Carneiro, W. M. A.; Coelho, M. C. S. G. Vitivinicultura nordestina: caracteristicas e perspectivas; Carneiro, W. M. A., Coelho, M. C. S. G., Eds.; Banco do Nordeste do Brasil: Fortaleza, CE, 2007; Vol. 19, p 135.

(2) Abe, L. T.; Mota, R. V.; Lajolo, F. M.; Genovese, M. I. Compostos fenólicos e capacidade antioxidante de cultivares de uvas Vitis labrusca L. e Vitis vinifera L. Cienc. Tecnol. Aliment. 2007, 27, 394-400.

(3) Freire, L.; Passamani, F. R. F.; Thomas, A. B.; Nassur, R. C. M. R.; Silva, L. M.; Paschoal, F. N.; Pereira, G. E.; Prado, G.; Batista, L. R. Influence of physical and chemical characteristics of wine grapes on the incidence of Penicillium and Aspergillus fungi in grapes and ochratoxin A in wines. Int. J. Food Microbiol. 2017, 241, 181-190.

(4) Ribéreau-Gayon, P.; Glories, Y.; Maujean, A.; Dubourdieu, D., Eds. Part One The Chemistry of Wine. In Handbook of Enology: the Chemistry of Wine Stabilization and Treatments, 2nd ed.; J. Wiley \& Sons: Chichester, West Sussex, 2006; Vol. 2, pp 3-230.
(5) Toaldo, I. M.; Cruz, F. A.; Alves, T. D. L.; Gois, J. S.; Borges, D. L. G.; Cunha, H. P.; Silva, E. L.; Bordignon-Luiz, M. T. Bioactive potential of Vitis labrusca L. grape juices from the Southern Region of Brazil: phenolic and elemental composition and effect on lipid peroxidation in healthy subjects. Food Chem. 2015, 173, 527-535.

(6) Otteneder, H.; Majerus, P. Occurrence of ochratoxin A in wines: Influence of the type of wine and its geographical origin. Food Addit. Contam. 2000, 17, 793-798.

(7) Belli, N.; Marín, S.; Sanchis, V.; Ramos, A. J. Influence of water activity and temperature on growth of isolates of Aspergillus section Nigri obtained from grapes. Int. J. Food Microbiol. 2004, 96, 19-27.

(8) Rousseaux, S.; Diguta, C. F.; Radoï-Matei, F.; Alexandre, H.; Guilloux-Bénatier, M. Non-Botrytis grape-rotting fungi responsible for earthy and moldy off-flavors and mycotoxins. Food Microbiol. 2014, $38,104-121$.

(9) Battilani, P.; Giorni, P.; Pietri, A. Epidemiology of toxin producing fungi and ochratoxin A occurrence in grape. Eur. J. Plant Pathol. 2003, 109, 715-722.

(10) Leong, S. L.; Hocking, A. D.; Pitt, J. I.; Kazi, B. A.; Emmett, R. W.; Scott, E. S. Black Aspergillus spp. in Australian vineyards: from soil to ochratoxin A in wine. In Advances in Food Mycology; Hocking, A. D., Pitt, J. I., Samson, R. A., Thrane, U., Eds.; Springer: New York, 2006; pp 158-171.

(11) Gareis, M. Maskierte Mykotoxine. Ubers Tierernahrung. 1994, 22, 104-113.

(12) Kovalsky Paris, M. P.; Schweiger, W.; Hametner, C.; StüCkler, R.; Muehlbauer, G. J.; Varga, E.; Krska, R.; Berthiller, F.; Adam, G. Zearalenone-16-O-glucoside: a new masked mycotoxin. J. Agric. Food Chem. 2014, 62, 1181-1189.

(13) Berthiller, F.; Crews, C.; Dall'Asta, C.; De Saeger, S.; Haesaert, G.; Karlovsky, P.; Oswald, I. P.; Seefelder, W.; Speijers, G.; Stroka, J. Masked mycotoxins: a review. Mol. Nutr. Food Res. 2013, 57, 165186.

(14) Coleman, J. O. D.; Blake-Kalff, M. M. A.; Davies, T. G. E. Detoxification of xenobiotics by plants: Chemical modification and vacuolar compartmentation. Trends Plant Sci. 1997, 2, 144-151.

(15) Sewald, N.; von Gleissenthall, J. L.; Schuster, M.; Müller, G.; Aplin, R. T. Structure elucidation of a plant metabolite of 4desoxynivalenol. Tetrahedron: Asymmetry 1992, 3, 953-960.

(16) Hildebrand, A. A.; Kohn, B. N.; Pfeiffer, E.; Wefers, D.; Metzler, M.; Bunzel, M. Conjugation of the Mycotoxins Alternariol and Alternariol Monomethyl Ether in Tobacco Suspension Cells. J. Agric. Food Chem. 2015, 63, 4728-4736.

(17) Jackson, R. S. Chemical Constituents of Grapes and Wine. In Wine Science - Principles and Applications, 3rd ed.; Jackson, R. S., Ed.; Academic Press: San Diego, CA, 2008; pp 270-323.

(18) Association of Official Analytical Chemists-AOAC. Official Methods of the Association of the Agricultural Chemists, 19th ed.; Latimer, G. W., Ed.; AOAC International: Gaithersburg, MS, 2012; p 1410.

(19) Instituto Adolfo Lutz. Métodos fisico-químicos para análise de alimentos, 4th ed.; Zenebon, O.; Pascuet, N. S.; Tiglea, P., Eds.; Instituto Adolfo Lutz: São Paulo, SP, 2008; p 1020.

(20) Giusti, M. M.; Wrolstad, R. E. Anthocyanins: characterization andmeasurement with uv-visible spectroscopy. In Current Protocols in Food Analytical Chemistry; Wrolstad, R. E., Ed.; John Wiley \& Sons: New York, 2001; pp 1-13.

(21) Paz, M.; Gúllon, P.; Barroso, M. F.; Carvalho, A. P.; Domingues, V. F.; Gomes, A. M.; Becker, H.; Longhinotti, E.; Delerue-Matos, C. Brazilian fruit pulps as functional foods and additives: Evaluation of bioactive compounds. Food Chem. 2015, 172, $462-468$.

(22) Fernández-Pachón, M. S.; Villaño, D.; Troncoso, A. M.; GarcíaParrilla, M. C. Determination of the phenolic composition of sherry and table white wines by liquid chromatography and their relation with antioxidant activity. Anal. Chim. Acta 2006, 563, 101-108.

(23) Prior, R. L.; Hoang, H.; Gu, L.; Wu, X.; Bacchiocca, M.; Howard, L.; Hampsch-Woodill, M.; Huang, D.; Ou, B.; Jacob, R. Assays for hydrophilic and lipophilic antioxidant capacity (oxygen 
radical absorbance capacity (ORACFL)) of plasma and other biological and food samples. J. Agric. Food Chem. 2003, 51, 32733279.

(24) Singleton, V. L.; Rossi, J. A. Colorimetry of total phenolics with phosphomolybdic-phosphotungstic acid reagents. Am. J. Enol. Vitic. $1965,16,144-158$.

(25) Freire, L.; Guerreiro, T. M.; Pia, A. K. R.; Lima, E. O.; Oliveira, D. N.; Melo, C. F. O. R.; Catharino, R. R.; Sant'Ana, A. S. Quantifying the variability of growth and ochratoxin A production in a grape-based medium by five different strains of Aspergillus carbonarius and Aspergillus niger and detection of modified forms of ochratoxin. Submitted.

(26) Wigmann, E. F.; Moreira, R. C.; Alvarenga, V. O.; Sant'Ana, A. S.; Copetti, M. V. Survival of Penicillium spp. conidia during deepfrying and baking steps of frozen chicken nuggets processing. Food Microbiol. 2016, 55, 1-6.

(27) Fiori, S.; Urgeghe, P. P.; Hammami, W.; Razzu, S.; Jaoua, S.; Migheli, Q. Biocontrol activity of four non- and low-fermenting yeast strains against Aspergillus carbonarius and their ability to remove ochratoxin A from grape juice. Int. J. Food Microbiol. 2014, 189, 4550 .

(28) Winston, P. W.; Bates, D. H. Saturated solutions for the control of humidity in biological research. Ecology 1960, 41, 232-236.

(29) Nathanail, A. V.; Varga, E.; Meng-Reiterer, J.; Bueschl, C.; Michlmayr, H.; Malachova, A.; Fruhmann, P.; Jestoi, M.; Peltonen, K.; Adam, G.; Lemmens, M.; Schuhmacher, R.; Berthiller, F. Metabolism of the Fusarium Mycotoxins T-2 Toxin and HT-2 Toxin in Wheat. J. Agric. Food Chem. 2015, 63, 7862-7872.

(30) Xia, J.; Wishart, D. S. Web-based inference of biological patterns, functions and pathways from metabolomic data using MetaboAnalyst. Nat. Protoc. 2011, 6, 743-760.

(31) Xia, J.; Wishart, D. S. Using metaboanalyst 3.0 for comprehensive metabolomics data analysis. Curr. Protoc. Bioinformatics. 2016, 55, 14.10.1-14.10.91.

(32) Perrone, G.; Mule, G.; Susca, A.; Battilani, P.; Pietri, A.; Logrieco, A. Ochratoxin A production and amplified fragment length polymorphism analysis of Aspergillus carbonarius, Aspergillus tubingensis, and Aspergillus niger strains isolated from grapes in Italy. Appl. Environ. Microbiol. 2006, 72, 680-685.

(33) Einloft, T. C.; Hoeltz, M.; Teixeira, T. R.; Oldoni, V. P.; Manfroi, V.; Noll, I. B. Survey of mycobiota, black Aspergillus and ochratoxin A occurrence on Brazilian wine grapes. Ann. Microbiol. 2017, 67, 59-64.

(34) Kumar, D.; Barad, S.; Sionov, E.; Keller, N. P.; Prusky, D. B. Does the Host Contribute to Modulation of Mycotoxin Production by Fruit Pathogens? Toxins 2017, 9, 280.

(35) Sanchis, V.; Magan, N. Environmental conditions affecting mycotoxins. In Mycotoxins in Food: Detection and Control; Magan, N., Olsen, M., Eds.; Elsevier Science: Burlington, ON, 2004; Vol. 103, pp 174-189.

(36) Paterson, R. R. M.; Venâncio, A.; Lima, N.; Guilloux-Bénatier, M.; Rousseaux, S. Predominant mycotoxins, mycotoxigenic fungi and climate change related to wine. Food Res. Int. 2018, 103, 478-491.

(37) Jiang, C.; Shi, J.; Zhu, C. Fruit spoilage and ochratoxin a production by Aspergillus carbonarius in the berries of different grape cultivars. Food Control 2013, 30, 93-100.

(38) Lasram, S.; Barketi, A.; Mliki, A.; Ghorbel, A. Growth and ochratoxin A production by Aspergillus carbonarius at different $\mathrm{pHs}$ and grape maturation stages. Lett. Appl. Microbiol. 2012, 54, 418-424.

(39) Teixeira, M. F. S.; Lima Filho, J. L.; Duran, N. Carbon sources effect on pectinase production from Aspergillus japonicus 586. Braz. J. Microbiol. 2000, 31, 286-290.

(40) Hashem, A.; Abd-Allah, E. F.; Al-Obeed, R. S.; Alqarawi, A. A.; Alwathnani, H. A. Effect of Carbon, Nitrogen Sources and Water Activity on Growth and Ochratoxin Production of Aspergillus carbonarius (Bainier) Thom. Jundishapur J. Microbiol. 2015, 8, e17569. (41) Palumbo, J. D.; O’Keeffe, T. L.; Mahoney, N. E. Inhibition of ochratoxin A production and growth of Aspergillus species by phenolic antioxidant compounds. Mycopathologia 2007, 164, 241-248.
(42) Crespo-Sempere, A.; Selma-Lázaro, C.; Palumbo, J. D.; González-Candelas, L.; Martínez-Culebras, P. V. Effect of oxidant stressors and phenolic antioxidants on the ochratoxigenic fungus Aspergillus carbonarius. J. Sci. Food Agric. 2016, 96, 169-177.

(43) Jard, G.; Liboz, T.; Mathieu, F.; Guyonvarc'h, A.; André, F.; Delaforge, M.; Lebrihi, A. Transformation of zearalenone to zearalenone-sulfate by Aspergillus spp. World Mycotoxin J. 2010, 3, $183-191$.

(44) Plasencia, J.; Mirocha, C. J. Isolation and characterization of zearalenone sulfate produced by Fusarium spp. Appl. Environ. Microbiol. 1991, 57, 146-150.

(45) Rolli, E.; Righetti, L.; Galaverna, G.; Suman, M.; Dall'Asta, C.; Bruni, R. Zearalenone Uptake and Biotransformation in Micropropagated Triticum durum Desf. Plants: A Xenobolomic Approach. J. Agric. Food Chem. 2018, 66, 1523-1532.

(46) Cramer, B.; Königs, M.; Humpf, H. Identification and in Vitro Cytotoxicity of Ochratoxin A Degradation Products Formed during Coffee Roasting. J. Agric. Food Chem. 2008, 56, 5673-5681.

(47) Bittner, A.; Cramer, B.; Harrer, H.; Humpf, H. Structure elucidation and in vitro cytotoxicity of ochratoxin $\alpha$ amide, a new degradation product of ochratoxin A. Mycotoxin Res. 2015, 31, 83-90.

(48) Bittner, A.; Cramer, B.; Humpf, H. Matrix Binding of Ochratoxin A during Roasting. J. Agric. Food Chem. 2013, 61, 12737-12743.

(49) Freire, L.; Sant'Ana, A. S. Modified mycotoxins: An updated review on their formation, detection, occurrence, and toxic effects. Food Chem. Toxicol. 2018, 111, 189-205.

(50) Ruhland, M.; Engelhardt, G.; Wallnöfer, P. R. Transformation of the mycotoxin ochratoxin $\mathrm{A}$ in plants. 2. Time course and rates of degradation and metabolite production in cell-suspension cultures of different crop plants. Mycopathologia 1996, 134, 97-102.

(51) Ovando-Martínez, M.; Ozsisli, B.; Anderson, J.; Whitney, K.; Ohm, J.; Simsek, S. Analysis of Deoxynivalenol and Deoxynivalenol-3glucoside in Hard Red Spring Wheat Inoculated with Fusarium graminearum. Toxins 2013, 5, 2522-2532.

(52) el Khoury, A.; Atoui, A.; Ochratoxin, A. General Overview and Actual Molecular Status. Toxins 2010, 2, 461-493.

(53) Wu, Q.; Dohnal, V.; Huang, L.; Kuča, K.; Wang, X.; Chen, G.; Yuan, Z. Metabolic Pathways of Ochratoxin A. Curr. Drug Metab. 2011, 12, 1-10.

(54) Malir, F.; Ostry, V.; Pfohl-Leszkowicz, A.; Malir, J.; Toman, J. Ochratoxin A: 50 Years of Research. Toxins 2016, 8, e191.

(55) Hoehler, D.; Marquardt, R. R.; McIntosh, A. R.; Xiao, H. Free Radical Generation as Induced by Ochratoxin A and Its Analogs in Bacteria (Bacillus brevis). J. Biol. Chem. 1996, 271, 27388-27394.

(56) Xiao, H.; Marquardt, R. R.; Frohlich, A. A.; Ling, Y. Z. Synthesis and Structural Elucidation of Analogs of Ochratoxin A. J. Agric. Food Chem. 1995, 43, 524-530.

(57) Dai, J.; Park, G.; Wright, M. W.; Adams, M.; Akman, S. A.; Manderville, R. A. Detection and characterization of a glutathione conjugate of ochratoxin A. Chem. Res. Toxicol. 2002, 15, 1581-1588. 